\title{
Challenges and Opportunities for the Traceability of (Biological) Medicinal Products
}

\author{
Kevin Klein ${ }^{1,2,3} \cdot$ Pieter Stolk $^{1,2,3}$
}

Published online: 2 May 2018

(c) The Author(s) 2018

\begin{abstract}
This article provides an overview of the current situation regarding the traceability of medicinal products, with a focus on drug safety and biologics. Limited traceability of biologics, in particular with regard to the batch number, is associated with incomplete recording of exposure information in clinical practice. The current pharmaceutical barcode standards in the EU do not support the automatic recording of dynamic product information, such as batch numbers and expiry dates, by means of electronic barcode scanning in clinical practice. New barcode requirements, such as the 2D DataMatrix with encoded batch numbers and expiry dates, provided on both the primary and the secondary package, can facilitate routine barcode scanning at all points in the supply chain in different healthcare settings. To build a full track-and-trace system for medicines with electronic capture of relevant exposure information, alignment with other topics, such as the Falsified Medicines Directive and initiatives to reduce medication errors, is needed to increase the buy-in from all stakeholders and to solve multiple issues with a joint effort.
\end{abstract}

Kevin Klein

k.klein1@uu.nl

1 Division of Pharmacoepidemiology and Clinical Pharmacology, Utrecht Institute for Pharmaceutical Sciences (UIPS), Utrecht University, Universiteitsweg 99, 3584 CG Utrecht, The Netherlands

2 Lygature, Escher, Utrecht, The Netherlands

3 Exon Consultancy, Amsterdam, The Netherlands

\section{Key Points}

Evidence points towards an association between the absence of brand names and/or batch numbers in adverse drug reaction (ADR) reports for biologics and shortcomings in the routine recording of this information in clinical practice.

The routine recording of dynamic product information such as batch numbers and expiry dates by means of electronic barcode scanning is not supported by the current barcoding standards for pharmaceuticals in the EU.

Efforts to achieve a full track-and-trace system with new barcoding standards and requirements to improve the traceability of medicinal products should be aligned with other drug safety topics, such as the Falsified Medicines Directive and initiatives to reduce medication errors.

\section{The Importance of Traceability for Medicinal Products}

The traceability of medicinal products throughout the healthcare chain is an essential part of providing good healthcare to patients. For example, in the hospital setting, a full track-and-trace system can enable electronic medication verification at the bedside, making sure that the right patient receives the right medicinal product, at the right time, in the right dosage form via the correct route of 
administration. In the outpatient and community setting, this safeguards the dispensing of the correct medicinal product to the patient. The lack of electronic medication verification is still an important source of medication errors. A full track-and-trace system could drastically reduce the risk of harm to patients caused by dispensing and administering the wrong medication [1-5]. Furthermore, a track-and-trace system that includes the expiry date can help simplify stock management, reduce waste (e.g. expired medicinal products) and help prevent stock-outs [6]. Finally, ensuring the traceability of medicinal products up to the batch number can accelerate batch recalls, thereby reducing the time that patients are potentially exposed to unsafe medication [6]. A full track-and-trace system including all relevant product information will ultimately expedite the reporting of adverse drug reactions (ADRs) with the relevant exposure information and thus allow regulators to take appropriate actions as rapidly as possible.

For biologics that are the subject of a suspected ADR, it is of particular importance that the batch number, in addition to the distinct product name (e.g. brand names or name of the manufacturer), is reported, as has been highlighted in the new pharmacovigilance legislation that came into effect in July 2012 [7]. Due to their distinctive properties related to the complexity of the manufacturing process, a degree of variability may exist between products from different manufacturers with the same active substance (e.g. due to follow-on versions referred to as biosimilars) and batches of the same product from the same manufacturer [8-10]. Although as of today some evidence has been found on batch-related issues for biologics, the actual impact remains unclear. However, since the importance of traceability should be regarded in the broader drug safety context, there certainly is ample scientific reason for ensuring a robust track-and-trace system of (biological) medicinal products throughout the supply chain.

In this article, we provide an overview of the current situation regarding the traceability of medicinal products, with a specific focus on drug safety and biologics. We discuss the current challenges in ensuring a full track-andtrace system and touch upon recent initiatives and potential future activities.

\section{How are Medicinal Products Traced in Clinical Practice?}

Medicinal products are generally distributed in three different packaging forms (Fig. 1). The tertiary package is usually used for logistical purposes, for example, for distribution from the wholesaler to the pharmacy; the secondary packaging (sometimes referred to as the outer package) is mostly used for inventory management within the pharmacy; and finally, the primary packaging is the level of the packaging that is in immediate contact with the medicinal product (e.g. vial, pre-filled syringe etc.).

Whereas the primary package can be at the single-unit level, the secondary package may also involve a multi-unit package (i.e. containing multiple primary packages as seen in the example of Fig. 1) ${ }^{1}$.

In general, medicinal product information such as brand name, batch number and expiry date are provided in $h u$ man-readable format (printed as letters and numbers) on both the primary and secondary product package levels, as required by EU regulations [11]. In addition, medicinal products are provided with a barcode that can be electronically scanned to identify the product, e.g. by reading out a global or national trade item number. This barcode can usually be found on the outer package (i.e. secondary package).

Unfortunately, linear barcodes, which are the current standard for pharmaceuticals in the EU, have a technical limitation: these barcodes can only encode static information and thus are not able to encode variable or dynamic data such as batch numbers and expiry dates. This means that the recording of this information in these circumstances still requires resource-intensive manual processes that can be prone to human errors [12, 13]. It also has implications for healthcare settings that have fully developed their routine workflows around an IT-infrastructure that relies on machine-readable data formats.

Nevertheless, novel barcode technology already exists that allows for the encoding of dynamic data. For example, two-dimensional (2D) barcodes, also referred to as the 2D DataMatrix, have the technical ability to encode dynamic data such as batch numbers and expiry dates, and could therefore facilitate the electronic recording of this information. In addition, the 2D DataMatrix is smaller in size compared to the current EU barcode standards, allowing it to be printed on smaller packages, which may, for example, enable the provision of barcodes on the smallest unit dose (i.e. primary package).

\section{Operational Aspects of Traceability in Clinical Practice}

To understand how traceability can be achieved in clinical practice, it is important to distinguish between different healthcare settings in which medicinal products are dispensed to patients. In Fig. 2, we present a simplified

\footnotetext{
${ }^{1}$ Exceptions may include pill bottles or blister packs, where the primary package often relates to multi-unit doses (often over-thecounter medicinal products), or orphan drugs, where all levels of the packaging could involve single-unit doses.
} 
Fig. 1 An overview of how a medicinal product is distributed throughout the supply chain, with regard to the different levels of packaging in which it is handled. Examples of the different packaging levels in the supply chain of a medicinal product (a) and a soda drink (b) are shown. *Some medicinal products need to be reconstituted under sterile/ aseptic conditions before being administered to the patient. In such situations, the active substance of the medicinal product is distributed in a formulation package (e.g. "injectable device") that is ready for use

\begin{tabular}{|l|l|l|l|}
\hline Tertiary package & Secondary package & Primary package & $\begin{array}{l}\text { Formulation package } \\
\text { (if prepared for } \\
\text { administration }\end{array}$ \\
& & & \\
\hline & & & \\
\hline (a) & & & \\
\hline
\end{tabular}

overview of three different settings through which medicinal products can be dispensed to a patient: (1) via the hospital pharmacy, for dispensing medicinal products to hospitalised patients (i.e. inpatient setting); (2) via the hospital outpatient pharmacy, for dispensing medicinal products to outpatients (e.g. patients who are discharged, day-care patients, or patients with specialty prescriptions) that can be administered outside the premises of the hospital; and (3) via the community pharmacy, for dispensing medicinal products in the primary care setting.

Different workflows apply to each of these settings and influence at what stage information can be recorded and in what way it can be processed. For example, medicinal products dispensed through the hospital pharmacy in the inpatient setting are administered to the patient by a healthcare professional within the hospital, whereas medicinal products dispensed through the outpatient or community pharmacy are administered by the patient at home. Within the hospital inpatient setting, medicinal products are generally dispensed in single-unit doses. Therefore the packaging that is dispensed to the individual patient in this setting is the primary package, or formulation package if the medicinal products are prepared for administration (e.g. reconstituted in the hospital pharmacy or at the bedside). In the hospital outpatient and community pharmacy settings, however, medicinal products are dispensed in the secondary package.

\section{Traceability of Biologics: Current Challenges}

From a drug safety perspective, the case of the traceability of biologics is especially relevant given its attention in EU legislation, as noted earlier. Several studies have investigated the traceability of biologics with regard to brand name and batch number in ADR reports. In these studies, performed in the national ADR databases of Italy and the Netherlands, as well as one study in the EudraVigilance database, the brand name for biologics in the ADR reports analysed in these studies was considered to be reasonably well captured, with estimates ranging from 76 to $95 \%$ (and up to $98 \%$ for biologics with expired patents) [14-16]. However, these studies also showed that batch number traceability was very poor, with estimates ranging between 5 and $21 \%$ of the ADR reports analysed. Although these studies also included ADR data from the years before the introduction of the pharmacovigilance legislation, a time trend analysis of the Dutch study indicated no increase of brand name and batch number reporting after the introduction of the pharmacovigilance legislation [15]. The three studies reached the same conclusion, pointing out the need to improve the traceability of biologics, in particular with regard to the batch number.

In the study from the Netherlands, it was concluded that the absence of brand names and/or batch numbers in ADR reports for biologics may be associated with the shortcomings in the recording of this information in clinical practice [15]. The study found that the product information on primary and secondary product packages is in most cases insufficient to support the automatic recording of product information through means of electronic barcode scanning. Specifically, pharmacists that participated in the study indicated that current barcodes do not carry batch number information (due to the technical limitations explained above) and that barcodes are often missing on single-unit packages, which limits the use of electronic barcode scanning in the hospital inpatient setting. It was therefore concluded that a new barcode standard is needed 


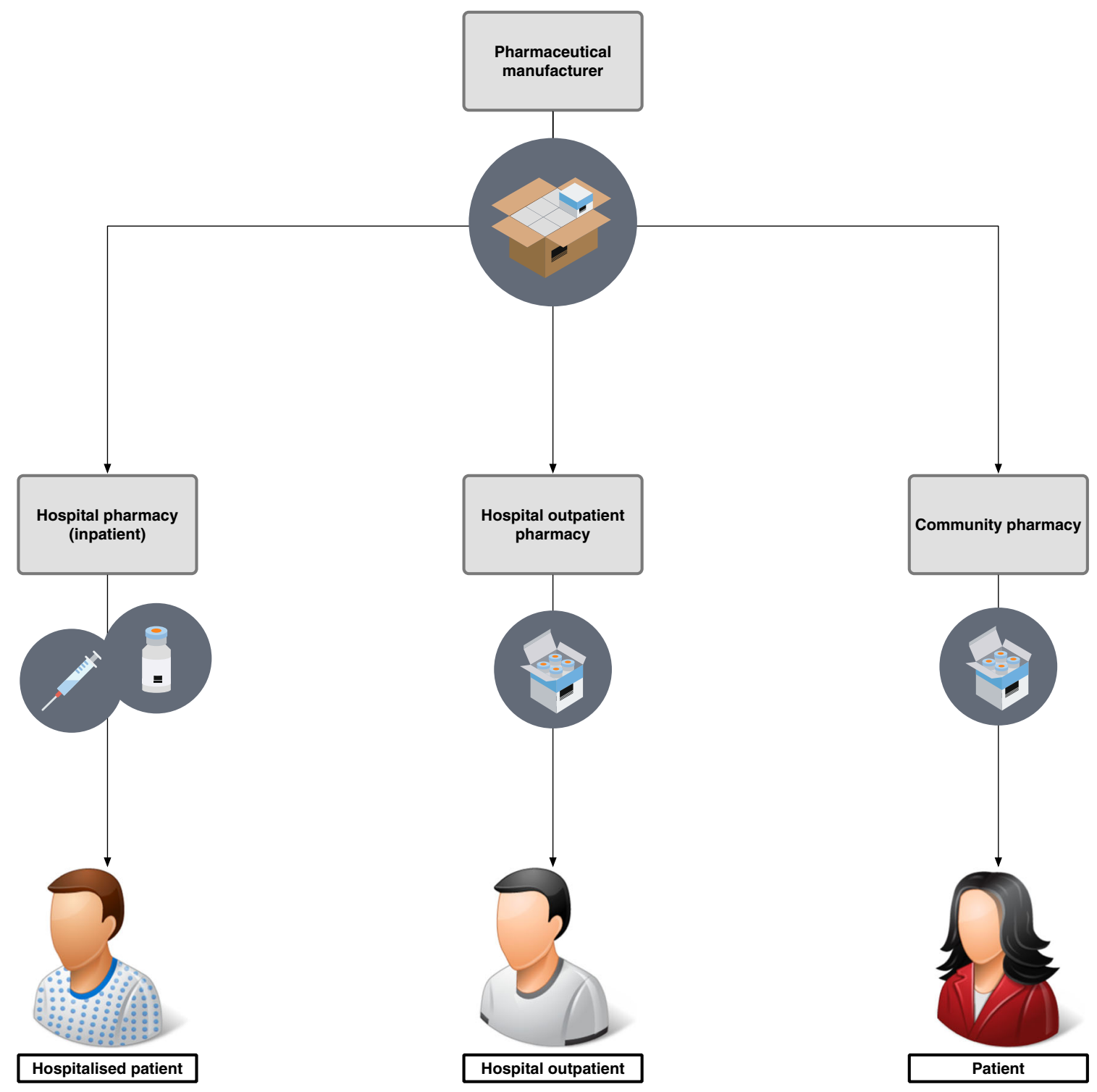

Fig. 2 An overview of the three different pharmacy settings in which medicinal products can be dispensed to patients. Left to right: Hospital pharmacy for dispensing medicinal products for the inpatient

(e.g. 2D DataMatrix), in which dynamic data such as batch numbers and expiry dates can be encoded and which are printed on every single-unit dose. This view is also supported by the European Association of Hospital Pharmacists (EAHP), who advocate for a new barcode standard and the mandatory inclusion of barcodes on the single-unit package of each medicinal product as part of their initiatives to reduce medication errors [17].

That today's technological possibilities of barcodes are only sporadically explored and implemented by pharmaceutical manufacturers can be seen from an assessment of product packages for a random sample of biologics from healthcare setting; hospital outpatient pharmacy for dispensing medicinal products to outpatients; and a community pharmacy dispensing medicinal products to patients in the primary care setting

the inpatient setting of a major academic teaching hospital in the Netherlands (Table 1). Of the eleven biologics that were assessed, the majority of the secondary packages are only equipped with linear barcodes, whereas the majority of the primary packages lacked a barcode. Minor exceptions relate to two manufacturers of infliximab, who added a 2D DataMatrix (including the batch number and the expiry date) on both the primary and secondary package. In one case, no barcodes could be found on either the primary or secondary package. This assessment also revealed that in many cases, medicinal products were provided with more than just one (linear) barcode. In some cases, up to four 
Table 1 Overview of the barcoding of a sample of biologics from the inpatient setting of a major academic teaching hospital in the Netherlands

\begin{tabular}{|c|c|c|c|c|}
\hline \multirow[t]{2}{*}{ Medicinal product } & \multicolumn{2}{|c|}{ Secondary package } & \multicolumn{2}{|l|}{ Primary package } \\
\hline & Barcode type & Encoded data & Barcode type & Encoded data \\
\hline Abatacept (Orencia) & Linear & $\mathrm{HIBC}$ & - & \\
\hline Aflibercept (Eylea) & Linear & NL-GTIN & - & \\
\hline Darbepoetin $^{\mathrm{a}}$ (Aranesp) & Linear & AU-GTIN & 2D DataMatrix & NL-GTIN \\
\hline Eculizumab (Soliris) & Linear & $\mathrm{BE}-\mathrm{CNK}$ & - & \\
\hline Epoetin beta ${ }^{\mathrm{a}}$ (NeoRecormon) & $\begin{array}{l}\text { Linear } \\
\text { Linear } \\
\text { Linear } \\
\text { Linear }\end{array}$ & $\begin{array}{l}\text { NL-GTIN } \\
\text { GE-PZN } \\
\text { BE-CNK } \\
\text { AU-GTIN }\end{array}$ & - & \\
\hline Infliximab (Remicade) & $\begin{array}{l}\text { 2D DataMatrix } \\
\text { Linear }\end{array}$ & $\begin{array}{l}\text { NL-GTIN; BAT; EXP } \\
\text { NL-GTIN }\end{array}$ & 2D DataMatrix & NL-GTIN; BAT; EXF \\
\hline Infliximab (Remsima) & $\begin{array}{l}\text { 2D DataMatrix } \\
\text { Linear } \\
\text { Linear } \\
\text { Linear }\end{array}$ & $\begin{array}{l}\text { NL-GTIN; BAT; EXP } \\
\text { NL-GTIN } \\
\text { GE-PZN } \\
\text { BE-CNK }\end{array}$ & 2D DataMatrix & NL-GTIN; BAT; EXF \\
\hline Moroctocog alfa (ReFacto) & $\begin{array}{l}\text { Linear } \\
\text { Linear }\end{array}$ & $\begin{array}{l}\text { NL-GTIN } \\
\text { FR-NTIN }\end{array}$ & - & \\
\hline Natalizumab (Tysabri) & - & & - & \\
\hline Omalizumab (Xolair) & Linear & NL-GTIN & - & \\
\hline Tocilizumab (RoActemra) & $\begin{array}{l}\text { 2D DataMatrix } \\
\text { Linear }\end{array}$ & $\begin{array}{l}\text { NL-GTIN; BAT; EXP } \\
\text { NL-GTIN }\end{array}$ & - & \\
\hline
\end{tabular}

$2 D$ two-dimensional, $A U$-GTIN Austria-Global Trade Item Number, BE-CNK Belgium-Code National Kode, FR-NTIN France-National Trade Item Number, GE-PZN Germany-Pharmazentralnummer, HIBC Health Industry Bar Code, NL-GTIN Netherlands-Global Trade Item Number, no barcode available, BAT Batch number, EXP Expiry date

${ }^{a}$ Packaged as multi-unit dose at the level of the secondary package

different barcodes could be found on a single secondary package, usually relating to different national trade item numbers. Furthermore, in many cases a 'pharmacode' could be found on the package, which is used by the manufacturer for internal control systems, but cannot be scanned in the pharmacy. Thus, the various different barcodes that can often be found on the packaging may also further complicate the workflows around the use of barcode technology.

\section{Addressing the Challenges of Traceability (of Biologics): What Needs to be Done?}

It is clear that there is a critical need for strengthening traceability systems in clinical practice for addressing public health needs such as drug safety. As more and more healthcare systems in EU Member States are making use of information technology to manage workflows for medicinal products, now is a crucial moment in time to explore possibilities of electronic recording of key product information for purposes of traceability. However, we want to highlight a number of regulatory and policy themes that could benefit from a better alignment.

\subsection{Better Alignment Between Regulators and Clinical Practice}

The current issues around the traceability of biologics highlight the need for a better regulatory alignment with clinical practice. An example of a potential lack of alignment can be seen in the updated guidelines for good pharmacovigilance practice (GVP) for better monitoring of biologics [18]. In the new guideline, the European Medicines Agency (EMA) refers to electronic data recording and, in particular, recommends "routine bar code scanning at all points in the supply chain" as one of the suggested methods for systematically capturing exposure information, including batch numbers. As we have pointed out here, the current barcode standards in the pharmaceutical sector make "routine bar code scanning at all points in the supply chain" impossible. This demonstrates that regulators may sometimes not be aware of practical challenges when it comes to implementing new regulations. This 
inadvertent lack of awareness could therefore impede the attainment of the goals of the regulations. We therefore want to underscore the importance for a thorough assessment of all relevant practical aspects, including potential bottlenecks, before new regulations are established.

\subsection{Linking Up Regulatory and Policy Topics that Can Benefit from a Joint Effort}

Regulatory and policy alignment is also needed to identify and combine different closely related topics that can (and should) be addressed with a joint effort. In the context of traceability, there are various different regulatory and policy initiatives working in parallel and isolation, both at the EU and national level. For example, in France, different barcoding requirements have already been implemented with the aim to improve patient safety $[19,20]$, while other EU Member States still have to address this issue. The Falsified Medicines Directive (FMD), discussed in Sect. 6, is another example. We believe that it is a missed opportunity if such initiatives focus on a single objective by working in silos and therefore leave other closely related objectives unaddressed, which could have otherwise have benefited if addressed in tandem. A better alignment between closely related topics could also increase the buyin from all stakeholders and share risks and burden for the implementation of new solutions. Activities around improving the traceability of biologics should therefore be aligned with other regulatory and policy topics related to traceability, such as reducing medical errors.

\subsection{Better Alignment Between Stakeholders to Achieve a Full Track-and-Trace System}

Enabling traceability with a full track-and-trace system requires alignment and buy-in from every stakeholder involved in the supply chain of medicinal products. Healthcare providers (hospitals, community pharmacies, etc.) will need to invest in appropriate technologies to enable the electronic recording of product information. Multi-directional laser scanners that allow for the scanning of different types of barcodes can facilitate the transition from current linear barcode standards to new standards such as the 2D DataMatrix. In addition to the technological transition in hospitals and pharmacies, hospital personnel need to be trained with these new work routines. Furthermore, pharmaceutical manufacturers should explore the possibilities to include (2D) barcodes with batch number and expiry dates on every primary package of a medicinal product. This will enable the electronic capture of exposure information in the hospital inpatient setting and eventually lead to a "closed loop" system in every setting [21]. Governments may encourage this transition by providing guidance, identifying cost-effective solutions and coordinating the process. However, an important part of this overall transition is the alignment between every stakeholder in the process. Only if all stakeholders act together, can this change be realised.

\section{The Falsified Medicines Directive: An Opportunity for Improving Traceability?}

It is important to mention the FMD in this context, as it is often brought up in discussions. The FMD is a piece of legislation that was adopted on October 2, 2015 and will come into effect as of February 9, 2019. The FMD aims to prevent the entry of counterfeit medicinal products into the supply chain by introducing mandatory safety features that allow for the verification of the authenticity of medicinal products before the medicine is dispensed [22, 23]. The two mandatory safety features of the FMD consist of (1) an anti-tampering device, allowing for the verification of whether a pack has been tampered with, and (2) a unique product identifier for the authentication of individual product packages, and must be applied on every secondary package of medicinal products by the marketing authorisation holder. The unique identifier will be provided both in human-readable format and in a machine-readable format, encoded in a 2D DataMatrix. Due to the recent decision to include the batch number and expiry date of the medicinal product in the unique product identifier, the FMD could serve as a 'launching pad' to improve the traceability of medicinal products. For example, in settings where the secondary package is managed (e.g. hospital outpatient and community pharmacy settings), the barcoding requirement by the FMD could be a first step towards the routine recording of batch numbers and expiry dates by means of electronic barcode scanning. Another possible opportunity of the current FMD barcode requirement that should be further examined in the future is its potential to improve the traceability for patient-reported ADRs, which increasingly rely on mobile phone applications, for example, by utilizing mobile barcode-scanning functionalities.

Given the absence of a requirement to include the 2D DataMatrix on the primary package, the current FMD does not yet enable its use for purposes of traceability in healthcare settings in which medicinal products are managed at the single-unit level (e.g. hospital inpatient setting). Nonetheless, the FMD in its current form should be further exploited as a potential opportunity for improving the traceability of medicinal products. This provides another interesting example of how different regulatory and policy topics can be better aligned with each other. 


\section{Conclusion}

In conclusion, building a full track-and-trace system for medicines with electronic capture of dynamic information such as batch numbers and expiry dates will allow for improved medication safety, more efficient supply chain management and contribute to a better pharmacovigilance system. This will require investments both in terms of time, resources, and regulatory efforts from every stakeholder involved. However, the value that can be captured both from a public health and from a cost-effectiveness perspective is significant. Moreover, the current regulatory ambitions for the pharmacovigilance of biologics, as laid down in EU legislation, cannot be met without a full trackand-trace system. The FMD shows that new barcode technology can already be implemented in the pharmaceutical sector. However, initiatives such as the FMD should be better aligned with other drug safety topics to explore its full potential to improve the traceability of medicinal products and in tandem address other public health objectives.

Acknowledgements We want to thank Robert van der Linde for his support with the assessment of medicinal product packages and for providing us with his extensive knowledge of information technology in the supply chain.

\section{Compliance with Ethical Standards}

Funding No sources of funding were used to assist in the preparation of this article.

Conflict of interest Kevin Klein and Pieter Stolk have no conflicts of interest that are relevant to the content of this article.

Open Access This article is distributed under the terms of the Creative Commons Attribution-NonCommercial 4.0 International License (http://creativecommons.org/licenses/by-nc/4.0/), which permits any noncommercial use, distribution, and reproduction in any medium, provided you give appropriate credit to the original author(s) and the source, provide a link to the Creative Commons license, and indicate if changes were made.

\section{References}

1. Poon EG, Keohane CA, Yoon CS, et al. Effect of bar-code technology on the safety of medication administration. N Engl J Med. 2010;362:1698-707. https://doi.org/10.1056/ NEJMsa0907115.

2. To err is human: building a safer health system. Washington, D.C.: National Academies Press, 2000. https://doi.org/10.17226/ 9728.

3. Seibert HH, Maddox RR, Flynn EA, Williams CK. Effect of barcode technology with electronic medication administration record on medication accuracy rates. Am J Health Syst Pharm. 2014;71:209-18. https://doi.org/10.2146/ajhp130332.

4. Ashcroft DM, Quinlan P, Blenkinsopp A. Prospective study of the incidence, nature and causes of dispensing errors in community pharmacies. Pharmacoepidemiol Drug Saf. 2005;14:327-32. https://doi.org/10.1002/pds.1012.

5. Cheung K-C, Bouvy ML, De Smet PAGM. Medication errors: the importance of safe dispensing. $\mathrm{Br} \mathrm{J}$ Clin Pharmacol. 2009;67:676-80. https://doi.org/10.1111/j.1365-2125.2009. 03428.x.

6. Romero A, Lefebvre E. Combining barcodes and RFID in a hybrid solution to improve hospital pharmacy logistics processes. Int J Inf Technol Manag. 2015;14:97. https://doi.org/10.1504/ IJITM.2015.068504.

7. Directive 2010/84/EU of the European Parliament and of the Council of 15 December 2010, amending as regards pharmacovigilance, Directive 2001/83/EC on the Community code relating to medicinal products for human use. Available at: http:// ec.europa.eu/health/files/eudralex/vol-1/dir_2010_84/dir_2010_ 84_en.pdf. Accessed 1 Feb 2018.

8. Schiestl M, Stangler T, Torella C, Čepeljnik T, Toll H, Grau R. Acceptable changes in quality attributes of glycosylated biopharmaceuticals. Nat Biotechnol. 2011;29:310-2. https://doi.org/ 10.1038/nbt.1839.

9. Ramanan S, Grampp G. Drift, evolution, and divergence in biologics and biosimilars manufacturing. BioDrugs. 2014;28:363-72. https://doi.org/10.1007/s40259-014-0088-z.

10. European Medicines Agency \& European Commission. Biosimilars in the EU-information guide for healthcare professionals. Available at: http://www.ema.europa.eu/docs/en_GB/document library/Leaflet/2017/05/WC500226648.pdf. Accessed 1 Feb 2018.

11. European Commission. Directive 2001/83/EC of the European Parliament and of the Council of 6 November 2001 on the Community code relating to medicinal products for human use. Available at: https://ec.europa.eu/health/sites/health/files/files/ eudralex/vol-1/dir_2001_83_consol_2012/dir_2001_83_cons_ 2012_en.pdf. Accessed 1 Feb 2018.

12. The European Association of Pharmaceutical Full-line Wholesalers (GIRP). Delegated Act on the detailed rules for a unique identifier for medicinal products for human use, and its verification-GRIP reply. Available at: https://ec.europa.eu/health// sites/health/files/files/falsified_medicines/2012-06_safetyfeatures/girp_en.pdf. Accessed 1 Feb 2018.

13. German Association of Full line Wholesalers (PHAGRO). Response to "Delegated Act on the Detailed Rules for a Unique Identifier for Medicinal Products for Human use, and its Verification." Available at: https://ec.europa.eu/health//sites/health/ files/files/falsified_medicines/2012-06_safety-features/phagro_ en.pdf. Accessed 1 Feb 2018.

14. Cutroneo PM, Isgrò V, Russo A, et al. Safety profile of biological medicines as compared with non-biologicals: an analysis of the Italian spontaneous reporting system database. Drug Saf. 2014;37:961-70. https://doi.org/10.1007/s40264-014-0224-1.

15. Klein K, Scholl JHG, Vermeer NS, et al. Traceability of biologics in the Netherlands: an analysis of information-recording systems in clinical practice and spontaneous ADR reports. Drug Saf. 2016;39:185-92. https://doi.org/10.1007/s40264-015-0383-8.

16. Vermeer NS, Straus SMJM, Mantel-Teeuwisse AK, et al. Traceability of biopharmaceuticals in spontaneous reporting systems: a cross-sectional study in the FDA Adverse Event Reporting System (FAERS) and EudraVigilance databases. Drug Saf. 2013;36:617-25. https://doi.org/10.1007/s40264-013-0073-3.

17. European Association of Hospital Pharmacists (EAHP). EAHP statement on the need for barcoding of the single dose administered in hospitals. Available at: http://www.eahp.eu/sites/default/ files/files/Barcode_2012\%20pdf.pdf. Accessed 1 Feb 2018.

18. European Medicines Agency. Guideline on good pharmacovigilance practices (GVP) - product- or population-specific considerations II: biological medicinal products. Available at: http:// 
www.ema.europa.eu/docs/en_GB/document_library/Scientific_ guideline/2016/08/WC500211728.pdf. Accessed 1 Feb 2018.

19. Manufacturing Chemist. France is first to set the code. Available at: https://www.manufacturingchemist.com/technical/article_ page/France_is_first_to_set_the_code/60653. Accessed 2 Feb 2018.

20. GS1. GS1 DataMatrix - a tool to improve patient safety through visibility in the supply chain. Available at: https://www.gs1.org/ docs/healthcare/MC07_GS1_Datamatrix.pdf. Accessed 2 Feb 2018.

21. Lenderink BW, Egberts TCG. Closing the loop of the medication use process using electronic medication administration registration. Pharm World Sci PWS. 2004;26:185-90.

22. European Commission. Directive 2011/62/EU of the European Parliament and of the Council of 8 June 2011 amending Directive
2001/83/EC on the Community code relating to medicinal products for human use, as regards the prevention of the entry into the legal supply chain of falsified medicinal products. Available at: https://ec.europa.eu/health/sites/health/files/files/ eudralex/vol-1/dir_2011_62/dir_2011_62_en.pdf. Accessed 2 Feb 2018.

23. European Commission. Commission Delegated Regulation (EU) 2016/161 of 2 October 2015 supplementing Directive 2001/83/ EC of the European Parliament and of the Council by laying down detailed rules for the safety features appearing on the packaging of medicinal products for human use. Available at: https://ec.europa.eu/health/sites/health/files/files/eudralex/vol-1/ reg_2016_161/reg_2016_161_en.pdf. 